\section{ACID ASPIRATION IN OBSTETRICS}

\section{DEAR SIR,}

Dewan and associates (Can. Anaesth. Soc. J, 29:27, 1982) mention the fact that anticholinergics have been shown to impair lower oesophageal sphincter function, but they dismiss this problem as one that "... properly applied cricoid pressure can overcome ...". I believe there is a flaw in their logic. Were cricoid pressure uniformly effective in preventing aspiration, the amount and acidity of gastric contents would be of no concern to the anaesthetist, and there would be no need for studies such as Dewan's. As Dewan, et al. themselves point out, however, even today, 20 years after the publication of Dr. Sellick's landmark study, 'Mendelson's syndrome remains a major cause of anestheticrelated maternal morbidity and mortality. Certainly cricoid pressure is the anaesthetist's first line of defense against aspiration, but we also do need to concern ourselves with the volume and composition of gastric contents and with the functional integrity of the lower oesophageal sphincter.

\footnotetext{
Sincerely,

James P. Southwick, M.D.,

Director, Obstetric Anesthesia,

Utah Valley Hospital,

1034 North 500 West,

Provo, Utah 84601 , U.S.A
}

\section{REFERENCE}

1. Sellick, B.A. Cricoid pressure to control regurgitation of stomach contents during induction of anaesthesia. Lancet 2: 404-406 (1961)

Effects of NeOstigmine ANd Pyridostigmine on SERUM Cholinesterase ACTIVITY

SiR,

Our paper on "Effects of Neostigmine and Pyridostigmine on Serum Cholinesterase Activity" has recently been published in the Can. Anaesth. Soc. J. (29: 55-58, 1982). Since the submission of our results for publication, the data on the enzyme activity have been subjected to a more detailed pharmacokinetic analysis. The results in a typical subject are given in the figure. The lines of best fit were obtained with a computer and the data are shown not in terms of drug levels, but in terms of diminishing levels of inactive enzyme.

From the terminal slopes of the "decay curves" the half lives of neostigmine and

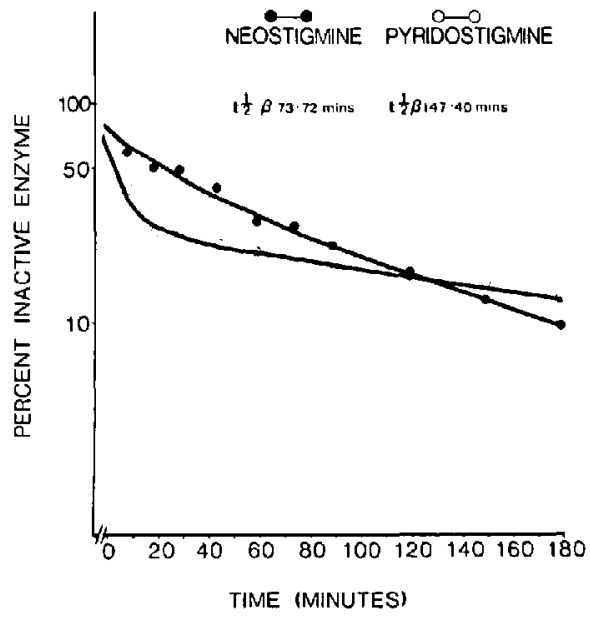

pyridostigmine regarding effects on serum cholinesterase activity were calculated to be approximately 74 minutes and 147 minutes respectively. This is in contrast to the half lives of the two drugs themselves which are considerably shorter, ${ }^{1,2}$ indicating a longer lasting effect at the neuromuscular junction than is reflected by the drug levels.

Although the half lives of the two drugs in terms of their effect on serum cholinesterase activity must be considered if suxamethonium is to be given following a previous administration of these anticholinesterase agents, the individual levels of enzyme activity in a particular patient would be equally important.
R.K. Mirakhur
R.S.J. Clarke
P.S. Collier
Department of Anaesthetics, The Queen's University of Belfast, Whitlaw Medical Building 97 Lisburn Road, Belfast BT9 7BL, N. Ireland.

\section{REFERENCES}

1. Williams, N.E., Calvey, T.N. \& Chan, K. Clearance of neostigmine from the circulation during the natagonism of neuromuscular block. Brit. J. Anaesth. 50: 1065 (1978)

2. BaKer, P.R., CalveY, T.N., Chan, K., MACNEE, C.M. \& TAYLOR, K. Plasma clearance of neostigmine and pyridostigmine in the dog. Br. J. Pharmacol. 63: 509 (1978). 